\title{
ARTICLES
}

\section{A COMPARATIVE STUDY ON PSYCHOLOGICAL PROBLEMS AMONG RETIRED PEOPLE IN SELECTED URBAN AND RURAL AREAS OF DISTRICT HOSHIARPUR, PUNJAB.}

Mrs. Rajwant Kaur* | Dr. Krishna Chauhan**

* Ph.D. Scholar, Himalayan University, Itanagar, Arunachal Pradesh, India.

** Principal, Shimla Nursing College, Annadale, Himachal Pradesh, India. DOI: http://doi.org/10.47211/idcij.2020.v07i03.003

Received $22^{\text {nd }}$ May 2020, Accepted $5^{\text {th }}$ June 2020, Available online $10^{\text {th }}$ July 2020.

\section{ABSTRACT}

Mental health problems consistently exist in societies around the world and its incidence is rising globally. Retirement is the point where a person stops employment completely. A person may also semi-retire by reducing work hours. Psychological problems are a concern for older adults, and have been shown to lead to admission to a nursing home, functional decline, and finally, to death. The largely limited availability and accessibility of health professionals and services in rural areas are among the most recognised barriers to appropriate use of health services by the rural people. These and other access barriers, especially, the lack of affordable and available transportation, limited income, and health insurance coverage, are critical for rural elders who face additional problems with physical frailty and the lack of social support.

Key Words: Problem, Retired People, Psychological, Mental Health.

\section{ABOUT AUTHORS:}

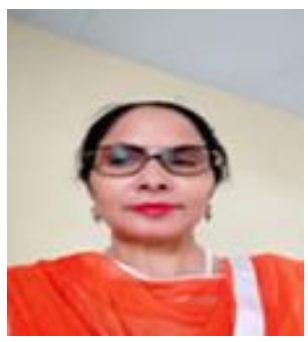

Author Mrs. Rajwant Kaur is a Research Scholar at Himalayan University in Itanagar, Arunachal Pradesh, India.

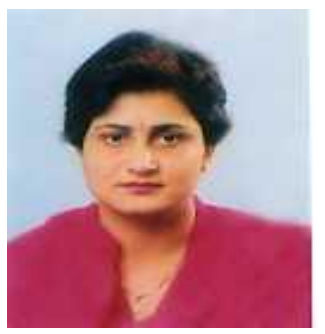

Author Dr. Krishna Chauhan is the Principal at Shimla Nursing College, Shimla. She has presented papers in various conferences and also has many publications to her name. 


\section{NEED FOR THE STUDY}

India has acquired the label of "an aging nation" with 7.7 percent of its population being more than 60 years old. Changes in population structure will have several implications for health, economic security, family life and well-being of people.

Mental health problems consistently exist in societies around the world and its incidence is rising globally. The recent rise in suicidal attempts and psychiatric disorders within our society calls for more vigilance in efforts to determine the amount, type, variety and distribution of mental disorders in our increasingly modernised environment. However, most mental health services are only easily accessible in urban areas. Rural communities, worldwide, are similarly facing the challenges in obtaining equitable and adequate mental and behavioural healthcare services. Moreover, suicide rates are unexpectedly higher in rural communities than in metropolitan communities. The suicide rate of males aged between 15 to 24 years in remote areas was approximately twice that of their city counterparts.

Retirement is the point where a person stops employment completely. A person may also semi-retire by reducing work hours. Many people choose to retire when they are eligible for private or public pension benefits, although some are forced to retire when physical conditions no longer allow the person to work anymore (by illness or accident) or as a result of legislation concerning their position. In most countries, the idea of retirement is of recent origin, being introduced during the late 19th and early 20th centuries. Previously, low life expectancy and the absence of pension arrangements meant that most workers continued to work until death. Germany was the first country to introduce retirement in 1880.

Psychological problems are a concern for older adults, and have been shown to lead to admission to a nursing home, functional decline, and finally, to death. Since the advent of urbanisation of society, a rural lifestyle has been purported to lower the risk of psychological problems. Features of urban life, such as overcrowding, poor working conditions and a disconnection from traditional supports were thought to predispose urban residents to mental health problems. At present, there is little research into these factors.

A rural residence could have both positive and negative effects on the risks of psychological problems. Contextual factors that could lessen the risk for psychological problems in rural areas include the presumed idyllic physical environment, residential stability, close social ties and stable social networks. As well, individual characteristics of rural residents such as resilience, independence and self-sufficiency may reduce the risk of psychological problems. However, other factors of rural living may increase the risk of psychological problems. Notably, economic decline, long travel distances, limited services and amenities and stark physical environments may lead to psychological problems. Furthermore, individual characteristics such as low educational attainment or low income may predispose people in rural areas to psychological problems.

Unfortunately, all too many depressed seniors fail to recognise the symptoms of psychological problems, or do not take the steps to get the help they need. There are many reasons for psychological problems in older adults and the elderly and they are so often overlooked.

The largely limited availability and accessibility of health professionals and services in rural areas are among the most recognised barriers to appropriate use of health services by the rural people. These and other access barriers, especially, the lack of affordable and available transportation, limited income, and health insurance 


\section{ARTICLES}

coverage, are critical for rural elders who face additional problems with physical frailty and the lack of social support.

So, there are many variations in the perception of psychological problem symptoms and the differences in sources of psychological problems between rural and urban elderly people. It has been sought to be compared in this study. Therefore, this study will be helpful to know about the psychological problems prevalent among retired people and furthermore, a comparison can be done between psychological problems faced by urban and rural retired people. This calls for review of the evidence for effective interventions and therapeutic approaches that can support elderly people and their families.

Working as a community researcher, it has been observed that retired people are facing psychological problems due to low finances, low self-esteems, dependency and ignorance. So there is need for better understanding of such crucial aspects. This will further lead to more information on psychological problems among retired people in urban and rural settings and that will add to the literature on psychological problems. It will help to find out the risks associated with such problems which will be useful for further investigations.

\section{STATEMENT OF THE PROBLEM}

'A comparative study on psychological problems among retired people in selected urban and rural areas of district Hoshiarpur, Punjab.'

\section{PURPOSE OF THE STUDY}

The purpose of the study is to compare psychological problems among retired people in selected urban and rural areas of the district of Hoshiarpur in Punjab.

\section{OBJECTIVES}

- To assess the psychological problems among retired people in urban area.

- To assess the psychological problems among retired people in rural area.

- To compare the psychological problems among retired people in urban and rural areas.

- To find out the relationship of the psychological problems with selected variables like age, gender, marital status, type of families, family income, type of retirement etc. of the retirees.

\section{DISCUSSION}

Retirement brings about many changes in the personal and social lives of retired persons. Economic problems, physical and physiological problems, psycho-social and social problems are some of the specific problems faced by a retired person. Generally, there are lowering of income, loss of status, decrease in socialisation, changes of activity and life styles, uncertainty about the future, difficulty in utilisation of time and a search for a new identity and status after retirement. Factors such as personality, attitude and social behavioural patterns seem to be critical for adjusting to retirement.

In the process of retirement, loss of status, loss of identity/ recognition, loss of source of income, progressive physical ageing, and emotional stress: the connotations of letting go can seem overwhelmingly negative. Organisational culture and societal pressure frequently reinforce this negativity. It is clear that the problems of the retirement syndrome have to be addressed on both an individual and organisational level. Organisations are notoriously negligent regarding retired people (aged persons). People on the verge of retirement are all too often left to fend for themselves with no help or preparation from the organisation. And many of them 


\section{ARTICLES}

sink; they plunge down into bitterness, resentment, and depression through their own inability (or unwillingness) to face up to reality and let go. John Simon was a leading executive with an investment bank. His experience of letting go reflects many of the negative and damaging effects that lack of personal preparation can have: "Well, of course I didn't want to go. Nobody ever does. They might talk a lot of rubbish about looking forward to retirement, but they're only trying to make the best of it. They had the cheek to offer me early retirement when I was fifty. I thought it was a joke at first and couldn't believe it when I realised they were serious." He was unwilling to go and refused their offer of a leaving-celebration. Finally he had to go and came to terms with his position but at a high cost.

Retirees have numbers of worries about having nothing to do, which is why they put so much preparatory effort into restructuring their life. Many were prepared to manage on less income and in fact they moved to a smaller house before their retirement, because their house condition was not good, it needed a lot of maintenance. With the children out of the house, it had become far too big for them.

Not everybody has Victor's (another retiree case) foresight and up-front approach, of course, and not everybody facing the necessity of letting go has either the time or the interest to prepare as they did. For Victor, retirement was an event, and a positive one at that. In most companies/ departments, unfortunately, retirement planning is viewed as largely a personal concern, and management provides very little or no feedback or guidance. In view of the effect that senior executives' poorly managed departure can have on company morale, these policies are more dangerous for the retirees. It may reflect a company/ department's philosophy that is equally blinkered. Today organisations are tempted to ease out senior people at early ages for several reasons: early-retirement policies can be seen as a way of rejuvenating the organisation appointing younger people to save cost.

Worry, doubt, self-interest, and despair are the furies that destroy a person's spirit. We need to go beyond Benjamin Disraeli's lament that "youth is a blunder; manhood a struggle; old age a regret." Retirement and old age may seem a long way off to many of us. But on the day they come, it will be too late in the day to do anything about them. If we sow little but only weeds at the height of our life career, we cannot expect to harvest a valuable crop later. We need to own our own lives now and at every stage we enter; and that kind of ownership requires that we diversify our interests and keep on learning. As Aristotle once said, "Education regarding preparation is the best policy and transition into old age." In addition to creating new interests, we need to invest in creating good relationships. In fact, that is the best creation we can make. If we want to chalk out a meaningful end to our life we must make sure to make happy moments in our earlier life.

\section{REFERENCES:}

1. Giscard D'Estaing, V. Le pouvoiret la vie. Vol. 11: L'affrontement. Paris: Compagnie 12, 1991.

2. Quoted in The Economist, June 8, 1991, p. 110. Graff, H. F. “When the Term's Up, It's Better to Go Gracefully." International Herald Tribune, Jan. 26, 1988, p. 5.

3. Kearns, D. Lyndon Johnson and the American Dream. New York: HarperCollins, 1976. Ross, J. M., and others. Father and Child. Boston: Little, Brown, 1982. 